\title{
Initial evidence for Sec62 as a prognostic marker in advanced head and neck squamous cell carcinoma
}

\author{
SILKE WEMMERT $^{1}$, YASMIN LINDNER ${ }^{1}$, JOHANNES LINXWEILER ${ }^{2}$, STEFAN WAGENPFEIL $^{3}$, \\ RAINER BOHLE ${ }^{4}$, MARCUS NIEWALD ${ }^{5}$ and BERNHARD SCHICK ${ }^{1}$ \\ ${ }^{1}$ Department of Otorhinolaryngology; ${ }^{2}$ Department of Medical Biochemistry and Molecular Biology, \\ Saarland University and Clinic of Urology and Pediatric Urology, Saarland University Medical Center; ${ }^{3}$ Institute of \\ Medical Biometrics, Epidemiology and Medical Informatics (IMBEI), Saarland University; ${ }^{4}$ Institute of Pathology; \\ ${ }^{5}$ Department of Radiotherapy and Radiooncology, Saarland University Medical Center, Homburg D-66421, Germany
}

Received January 14, 2015; Accepted November 27, 2015

DOI: $10.3892 / 01.2016 .4135$

\begin{abstract}
Head and neck squamous cell carcinoma (HNSCC) is a malignancy with an increasing incidence. To aid with the selection of the most appropriate therapy, biomarkers have become a specific research focus. Sec62 is involved in endoplasmic reticulum stress tolerance and cell migration, and has been identified as a novel prognostic marker for non-small cell lung cancer. In addition, Sec62 may be a promising candidate in HNSCC. Pretreatment biopsies of 35 patients with locally advanced HNSCC, who were treated with definitive chemoradiation therapy without prior surgery, were examined for the expression of Sec62 protein, as well as the expression of epidermal growth factor receptor (EGFR), p16 and survivin proteins. Immunohistological results were correlated with patient overall survival (OS) and progression-free survival (PFS) times. In the present patient cohort, 12/35 cases (34\%) demonstrated strong and 8/35 cases (23\%) moderate Sec62 staining intensity. Additionally, in $11 / 35$ cases (31\%), weak staining was observed, and only $4 / 35$ cases $(11 \%)$ were Sec62-negative. Notably, a high Sec62 protein level was associated with a significantly poorer OS and PFS $(\mathrm{P}=0.020$ and $\mathrm{P}=0.028$, respectively). Furthermore, higher nuclear survivin expression showed a weak trend for poorer OS rate $(\mathrm{P}=0.079)$, whilst neither cytoplasmic survivin, EGFR nor p16 influenced OS or PFS significantly. The present study indicated that Sec62 is a promising prognostic marker for HNSCC. Increased Sec62 protein expression may indicate a poorer prognosis in advanced HNSCC. As the present study was focused on patients treated by chemoradiation therapy, further studies with larger patient cohorts and alternative treatment approaches are required in order to define the prognostic value of Sec62 in HNSCC.
\end{abstract}

Correspondence to: Dr Silke Wemmert, Department of Otorhinolaryngology, Saarland University Medical Center, Kirrberger Strasse 100, Homburg D-66421, Germany

E-mail: silke.wemmert@uks.eu

Key words: Sec62, head and neck cancer, prognosis

\section{Introduction}

Head and neck squamous cell carcinoma (HNSCC) accounts for $>500,000$ newly diagnosed cases annually worldwide (1). The primary risk factors are tobacco use and alcohol consumption, which appear to exert a synergistic effect (2). Patient prognosis is largely determined by the extent of the tumor, as well as the presence of lymph node and distant metastases $(1,2)$. Furthermore, a unique subset of HNSCCs, particularly oropharyngeal tumors, are associated with human papillomavirus (HPV) infection, which has been demonstrated to be of significant prognostic value $(3,4)$. HPV-positive tumors are characterized by increased expression of p16 due to functional inactivation of retinoblastoma protein by the viral oncoprotein E7. Therefore detection of p16 by immunohistochemistry (IHC) is considered to be a robust marker of HPV infection in these tumors $(5,6)$.

In locally advanced HNSCC, concomitant chemoradiation therapy (CRT) has emerged as a useful treatment modality for organ preservation, treatment of unresectable disease and as an adjuvant therapy in resected high-risk disease (7). However, CRT is associated with significant short- and long-term treatment-associated morbidities and complications. Furthermore, histologically similar tumors receiving identical therapies may exhibit varying clinical outcomes, and a proportion of patients will not respond to CRT $(3-5,7)$. Therefore, identification of markers that predict the prognosis of advanced HNSCC treated by CRT will be significant for the improvement of clinical treatment decisions.

HNSCC is a heterogeneous disease with respect to its complex molecular abnormalities and tumor-associated proteome. Over 20 recurrent chromosomal alterations have been identified in invasive HNSCC, and gains at $3 \mathrm{q}, 11 \mathrm{q}$ and $12 \mathrm{q}$, as well as losses at $5 \mathrm{q}, 6 \mathrm{q}, 8 \mathrm{p}, 21 \mathrm{q}$ and $22 \mathrm{q}$ have been associated with poor prognosis (8-10). A number of tumor-associated markers have been identified for HNSCC carcinogenesis, and have been considered as potential reasons for various responses to therapy. They may also have value as prognostic markers in patients with HNSCC. Epidermal growth factor receptor (EGFR) and survivin are two candidates that have been investigated as promising prognostic biomarkers for HNSCC (11-17). 
EGFR, a transmembrane glycoprotein receptor, is encoded by the human epidermal growth factor receptor $1 / c-E R B B I$ proto-oncogene located on chromosome 7p12. Ligand binding causes activation of the intracellular tyrosine kinase domain, resulting in signal transduction involving proliferation, cell division and differentiation (18). EGFR is overexpressed in the majority of epithelial malignancies and a prognostic impact of EGFR overexpression has been identified in a number of types of human cancer, including ovarian, bladder, cervical, gastric, esophageal, breast, endometrial and colorectal cancer (19). Overexpression of EGFR has additionally been observed in $>80 \%$ of HNSCC cases and occurs early during head-neck carcinogenesis $(20,21)$. However, conflicting results have been reported from certain laboratories. Meta-analyses have discussed the effects of various clinicopathological parameters and evaluation methods for the prognostic value of $\operatorname{EGFR}(11,12)$.

Survivin, a member of the apoptosis inhibitor family located on chromosome 17q25.3, serves a significant role in cell cycle progression and is expressed in fetal tissues, as well as in a wide range of cancer tissues; however, it is not expressed in normal adult differentiated tissues $(22,23)$. Notably, survivin is detected as a cytoplasmic and nuclear protein in cancer patients. Nuclear survivin is suspected to control cell division, whereas cytoplasmic/mitochondrial survivin is considered to be cytoprotective (13). Consequently, intracellular localization of survivin in tumor cells has been analyzed as a prognostic marker in a number of patient-based studies, achieving differing results (13).

Gain of $3 q$ is the most frequently detected chromosomal alteration in HNSCC and has additionally been reported in numerous other tumor entities, including prostate, esophageal squamous cell, cervical squamous cell and non-small cell lung cancer (NSCLC) (24-27). Furthermore, an amplification of the chromosomal region $3 \mathrm{q}$ was identified as the most frequent genomic alteration in oropharyngeal squamous cell carcinoma (OSCC), independent of HPV status, and was significantly associated with advanced tumor stage in the total patient group, as well as in the non-HPV-associated subgroup (28). Notably, studies have identified SEC62 as the most commonly overexpressed gene within this $3 q$ region, based on increased messenger RNA and protein levels in prostate and thyroid cancer, as well as NSCLC (24,29-31). SEC62, a gene that encodes an endoplasmic reticulum (ER) transmembrane protein, has an essential function in cell migration (29) and ER stress tolerance (30). Furthermore, Sec62 overexpression has been demonstrated to be correlated with the presence of lymph node metastases (increased Sec62 levels in node-positive tumors compared with node-negative tumors) and tumor cell dedifferentiation (increased Sec62 levels in poorly-differentiated grade 3 tumors compared with grade 2 tumors) in NSCLC patients (31). Furthermore, it is reported to be associated with significantly poorer overall survival (OS), particularly in NSCLC with squamous differentiation (32).

In the present study, Sec62 expression was analyzed for the first time in HNSCC by IHC, and the results were correlated with the clinicopathological data of a cohort of 35 patients with advanced HNSCC treated by CRT. In addition, the immunohistological expression of EGFR, survivin and p16 as biomarkers of interest in HNSCC were investigated and included in a multiple regression analysis.

\section{Materials and methods}

Patient characteristics. The records of 35 patients treated at Saarland University Hospital (Homburg, Germany) between August 1996 and May 2006 were analyzed retrospectively. All patients exhibited newly diagnosed squamous cell carcinoma of the head and neck region. Informed consent was obtained from the patients and the study design was approved by the local ethics committee (reference \#218/10). The primary tumors were located as follows: Oropharynx, 24 cases (69\%); hypopharynx, 6 cases $(17 \%)$; larynx, 3 cases $(9 \%)$; and nasopharynx, 2 cases $(6 \%)$. The median age at diagnosis was 55 years (range, 43-74 years), and the mean Karnofsky performance index amounted to 8 (6-10). The cohort included 33 male patients $(94 \%)$ and 2 female patients $(6 \%)$. Smoking history data was not available. All tumors were classified as stage IV according to the International Union Against Cancer system (33), and distant metastases had been excluded.

All patients underwent simultaneous definitive CRT without prior surgery. A total dose of $72 \mathrm{~Gy}$ in single fractions of $1.2 \mathrm{~Gy}$ was administered 10 times/week and twice daily in a hyperfractionated manner (inter-fraction interval, $\geq 6 \mathrm{~h}$ ). A linear accelerator was used to apply $6 \mathrm{MV}$ photons and electrons. Chemotherapy was administered to all patients, and consisted of two cycles of cisplatin $\left(20 \mathrm{mg} / \mathrm{m}^{2}\right.$ for 5 days, for a total dose of $60 \mathrm{mg} / \mathrm{m}^{2}$ ) and fluorouracil (5-FU; continuous infusion of $600 \mathrm{mg} / \mathrm{m}^{2} /$ day on days 1-5) in 34 patients, or mitomycin and 5-FU in the remaining patient (continuous infusion of $600 \mathrm{mg} / \mathrm{m}^{2} /$ day $5-\mathrm{FU}$ on days $1-5$; single intravenous bolus injection of $10 \mathrm{mg} / \mathrm{m}^{2}$ mitomycin $\mathrm{C}$ on days 5 and 36 ). Follow-up time was defined from the date of diagnosis to the date of the final visit or date of mortality. The mean follow-up time was 52.2 months, with a minimum of 1.6 and a maximum of 203 months (median, 24 months). The clinicopathological characteristics of the patient group are presented in Table I.

Immunohistochemical staining. Slides from all biopsies were reviewed by one pathologist in order to select representative areas of the tumors for additional IHC analysis. The criteria were vital tumor tissue without necrosis and an estimate of $\geq 70 \%$ tumor cells in the analyzed tissue area.

Selected sections were deparaffinized and rehydrated using repeated xylene and graded alcohol washes. For antigen retrieval, slides were incubated with citrate buffer (for Sec62; $\mathrm{pH} 6.0$ for $1 \mathrm{~h}$ at $90^{\circ} \mathrm{C}$ ), Tris- $\mathrm{HCl}$ (for survivin; $\mathrm{pH} 9.0$ for $1 \mathrm{~h}$ at $95^{\circ} \mathrm{C}$ ) or Protease Type XIV (for EGFR; 2 min at room temperature; Sigma-Aldrich Chemie GmbH, Munich, Germany).

Primary antibody incubations for EGFR (clone E30; monoclonal mouse anti-human; \#M7239; Dako, Glostrup, Denmark; dilution, 1:50) and survivin (polyclonal rabbit anti-human; \#ab469; Abcam, Cambridge, UK; dilution, 1:250) were performed overnight at $4^{\circ} \mathrm{C}$. For Sec62, primary antibody incubation was conducted for $1 \mathrm{~h}$ at room temperature (affinity-purified, polyclonal rabbit antibody directed against the $\mathrm{COOH}$-terminal undecapeptide of human Sec62 protein; dilution, 1:200. This antibody was kindly provided by Dr Markus Greiner, Department of Medical Biochemistry and Molecular Biology, Saarland University, (Homburg/Saar, Germany) and was previously demonstrated to be of excellent sensitivity and specificity under denaturing and native 
Table I. Clinicopathological features of head and neck squamous cell carcinoma patients $(\mathrm{n}=35)$ and influence on survival time.

\begin{tabular}{|c|c|c|c|c|}
\hline \multirow[b]{2}{*}{ Clinicopathological feature } & \multicolumn{2}{|c|}{ Patients } & \multicolumn{2}{|c|}{ P-value } \\
\hline & Value & $\%$ & Overall survival & Progression-free survival \\
\hline Gender, $\mathrm{n}$ & & & 0.683 & 0.004 \\
\hline Male & 33 & 94 & & \\
\hline Female & 2 & 6 & & \\
\hline Age, years & & & $0.621^{\mathrm{a}}$ & $0.594^{\mathrm{a}}$ \\
\hline Median & 55 & & & \\
\hline Range & $43-77$ & & & \\
\hline \multicolumn{5}{|l|}{ Overall survival time, months } \\
\hline Mean/median & $54 / 29$ & & & \\
\hline Range & $2-203$ & & & \\
\hline Localization, $\mathrm{n}$ & & & 0.338 & 0.232 \\
\hline Oropharynx & 24 & 69 & & \\
\hline Hypopharynx & 6 & 17 & & \\
\hline Nasopharynx & 2 & 6 & & \\
\hline Larynx & 3 & 9 & & \\
\hline Karnofsky score, $\mathrm{n}$ & & & 0.053 & 0.216 \\
\hline 6 & 2 & 6 & & \\
\hline 7 & 8 & 23 & & \\
\hline 8 & 13 & 37 & & \\
\hline 9 & 11 & 31 & & \\
\hline 10 & 1 & 3 & & \\
\hline Tumor stage, $\mathrm{n}$ & & & 0.725 & 0.850 \\
\hline 2 & 3 & 9 & & \\
\hline 3 & 7 & 20 & & \\
\hline 4 & 25 & 71 & & \\
\hline Node stage, $\mathrm{n}$ & & & 0.213 & 0.245 \\
\hline 0 & 2 & 6 & & \\
\hline 1 & 4 & 12 & & \\
\hline 2 & 26 & 74 & & \\
\hline 3 & 3 & 9 & & \\
\hline
\end{tabular}

${ }^{\mathrm{a} C}$ Cox regression analysis.

conditions (30) Visualization of bound primary antibodies was performed with the Real Detection System (Dako) according to the manufacturer's protocol. p16 staining was performed with the CINtec ${ }^{\circledR}$ Histology kit (Roche Diagnostics $\mathrm{GmbH}$, Mannheim, Germany) according to the manufacturer's protocol. The slides were counterstained using hematoxylin (Merck Millipore, Darmstadt, Germany) and each analysis included positive and negative controls.

Staining intensity of EGFR and cytoplasmic survivin was scored as 0 (none), 1 (weak), 2 (moderate) or 3 (strong), and was considered to be high when the fraction of moderately and strongly stained cells within the tumor cell population was $>10 \%$. Furthermore, slides were considered to be survivin nuclear-positive when $>10 \%$ of all tumor cell nuclei were stained, regardless of the cytoplasmic staining level. p16 expression was dichotomized as p16-positive (strong nuclear or cytoplasmic staining in $\geq 70 \%$ of tumor cells) or p16-negative.
For Sec62, the cytoplasmic Sec62 staining intensity was scored as 0 (none), 1 (weak), 2 (moderate) or 3 (strong). The product of the scores for staining intensity and number of stained cells ( 0 , no stained cells; $1,<10 \% ; 2,10-50 \% ; 3,51-80 \%$; or $4,>80 \%$ ), defined as the immunoreactive score (IRS) according to Remmele and Stegner (34), was used. IRS scores from 0-2 were valued as negative, 3-4 as weak, 6-8 as moderate and 9-12 as strong; subsequently, these were dichotomized into low (IRS, <9) and high (IRS, 9-12) expression.

Statistical analysis. Statistical analysis was performed with SPSS version 20 (IBM SPSS, Armonk, NY, USA). OS was calculated as the time from diagnosis date to mortality date or the final documented follow-up date. Progression-free survival (PFS) was defined as the time from diagnosis date to the date of disease progression, the final documented follow-up date or mortality date from any cause. Survival curves were 
Table II. Immunohistochemical expression analysis according to various head and neck squamous cell carcinoma localization sites.

\begin{tabular}{|c|c|c|c|c|}
\hline \multirow[b]{2}{*}{ Protein } & \multicolumn{4}{|c|}{ Expression level (high/low, n) } \\
\hline & Oropharynx $(n=24)$ & Hypopharynx $(n=6)$ & Nasopharynx (n=2) & Larynx $(n=3)$ \\
\hline Sec62 & $10 / 14$ & $2 / 4$ & $0 / 2$ & $0 / 3$ \\
\hline EGFR & $11 / 13$ & $2 / 4$ & $2 / 0$ & $2 / 1$ \\
\hline p16 & $5 / 19$ & $0 / 6$ & $0 / 2$ & $0 / 3$ \\
\hline \multicolumn{5}{|l|}{ Survivin } \\
\hline Nuc & $15 / 9$ & $3 / 3$ & $1 / 1$ & $0 / 3$ \\
\hline Cyt & $15 / 9$ & $3 / 3$ & $0 / 2$ & $2 / 1$ \\
\hline Nuc+cyt & $20 / 4$ & $1 / 1$ & $5 / 1$ & $2 / 1$ \\
\hline
\end{tabular}

EGFR, epidermal growth factor receptor; nuc, nuclear; cyt, cytoplasmic.

Table III. Immunohistochemical expression of Sec62 in the cytoplasm on the basis of the IRS according to HNSCC site.

Sec62

HNSCC localization site

\begin{tabular}{lcccc}
\cline { 2 - 4 } expression level & Oropharynx & Hypopharynx & Nasopharynx & Larynx \\
\hline Strong (IRS 9-12) & 10 & 2 & - & - \\
Moderate (IRS 6-8) & 4 & 3 & 1 & 1 \\
Weak (IRS 3-4) & 7 & 1 & 1 & - \\
Negative (IRS 0-2) & 3 & - & - \\
\hline
\end{tabular}

-, not available. IRS, immunoreactive score; HNSCC, head and neck squamous cell carcinoma.

calculated by the Kaplan-Meier method and compared by the log-rank test and univariate Cox regression. The $\chi^{2}$ test was utilized to determine the association and differences between dichotomized variables, encompassing IHC expression and clinicopathological characteristics. $\mathrm{P}<0.05$ (two-sided) was considered to indicate a statistically significant difference. Reported P-values are unadjusted for the issue of multiple testing due to the screening nature of the present study.

\section{Results}

Immunohistological staining of EGFR, survivin, p16 and Sec62. Immunohistochemical EGFR staining revealed strong membranous and cytoplasmic signals in $17 / 35$ cases $(49 \%)$. Cytoplasmic survivin staining was observed in 20 cases (57\%). Using a cut-off value of $\geq 10 \%$ of tumor cells demonstrating positive nuclear staining signals, 19/35 cases (54\%) were classified as nuclear survivin-positive. Furthermore, in 28 cases $(80 \%)$ survivin was detected in the nucleus and/or cytoplasm of tumor cells. p16 expression was observed either to be generally absent, or present as strong and diffuse nuclear and cytoplasmic staining. Overexpression of p16 was observed in 5 tumors (14\%) and was restricted to OSCCs (5/24 tumors; 21\%). A summary of the observed staining levels for each candidate marker according to the tumor site is presented in Table II.

Strong Sec62 staining intensity was observed in 12/35 cases (34\%) and was primarily identified in OSCC (10/24 tumors). Furthermore, in 8 (23\%) and 11 HNSCC cases (31\%), moderate and weak staining was observed, respectively, whereas only 4 cases $(11 \%)$ were Sec62-negative in the analyzed representative tumor tissue samples (Table II; Fig. 1). The detailed results of Sec62 immunostaining with regard to IRS and tumor site are presented in Table III and Fig. 2. There was no association between tumor site and Sec62 expression level $\left(\chi^{2}, \mathrm{P}=0.458\right)$. Normal squamous epithelium demonstrated weak Sec62 staining in regenerating basal cells (stratum germinativum), while no immunoreactivity was observed in the more superficial cell layers (Fig. 1). As described previously (31), plasma cells within inflammatory infiltrates demonstrated strong Sec62 staining in all samples, irrespective of the Sec62 signals of adjacent tumor cells, due to their large amount of rough ER, thereby serving as internal positive controls (Fig. 1).

Correlation of protein expression with clinicopathological parameters. Analysis of clinicopathological parameters in the CRT-treated patient cohort revealed no statistically significant differences in OS with regard to gender, tumor localization, Karnofsky score, tumor grading and lymph node metastases (Table I).

A detailed analysis of potential correlations between the analyzed protein expression scores and the clinicopathological parameters of the patients was performed. With regard to tumor localization, only p16 overexpression was restricted to OSCCs (5/24 tumors; $\chi^{2}, \mathrm{P}=0.593$; Table II). Regarding survival, the expression levels of EGFR, cytoplasmic survivin or p16 were not significantly associated with $\mathrm{OS}(\mathrm{P}=0.585, \mathrm{P}=0.785$ and 

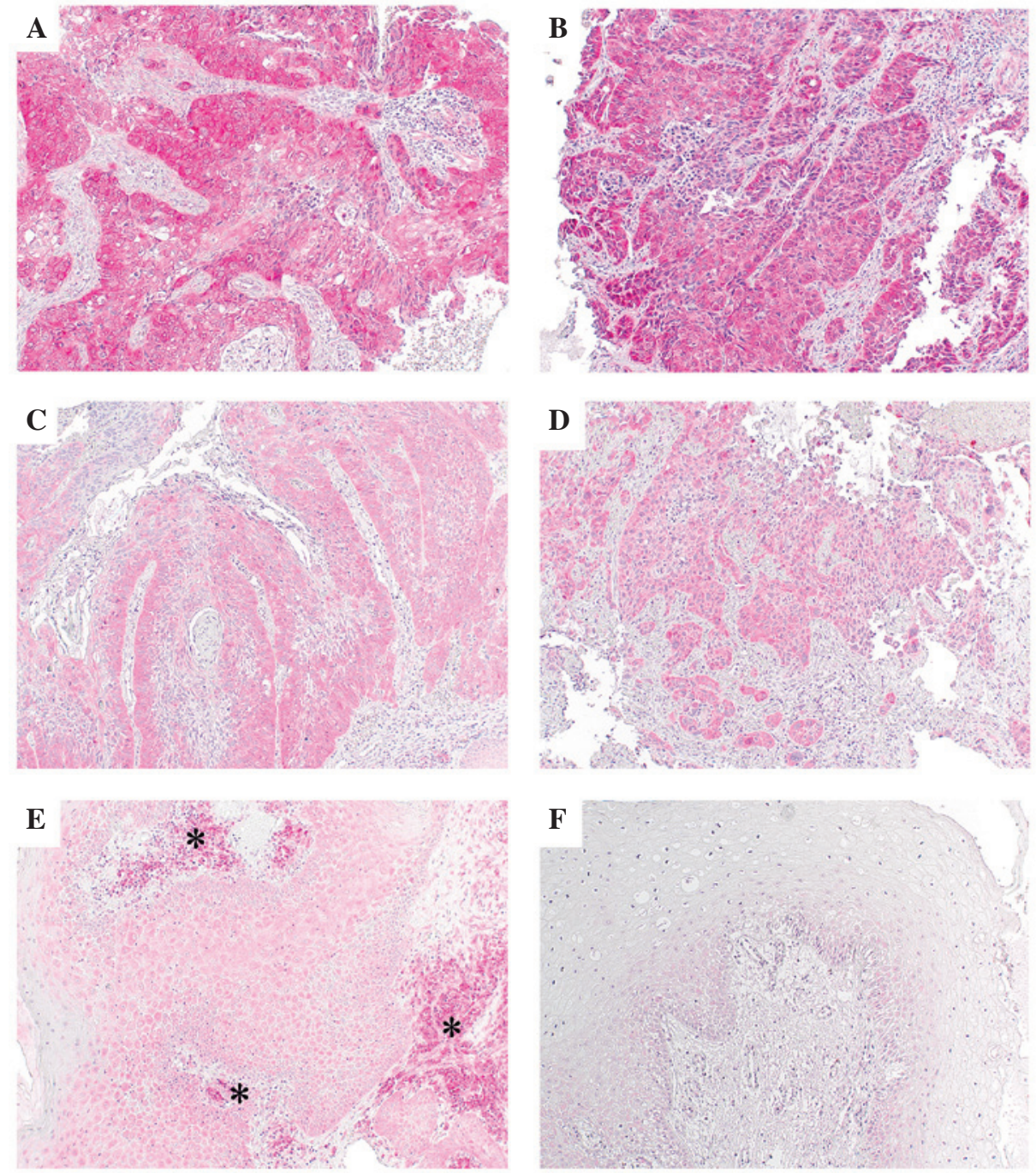

Figure 1. Sec62 immunostaining in head and neck squamous cell carcinoma. Representative microphotographs of strong Sec62-immunoreactivity in (A) hypopharyngeal and (B) oropharyngeal tumor site, moderate Sec62-immunoreactivity in (C) hypopharyngeal tumor sites, and weak Sec62-immunoreactivity in (D) hypopharyngeal and (E) oropharyngeal tumor sites. Plasma cells within inflammatory infiltrates (marked with asterisks) serve as internal positive controls due to their excessive amount of rough endoplasmic reticulum. (F) Normal epithelial tissue (oropharyngeal squamous epithelium) did not exhibit Sec62-immunoreactivity (magnification, x10). All sections were counterstained with hematoxylin.

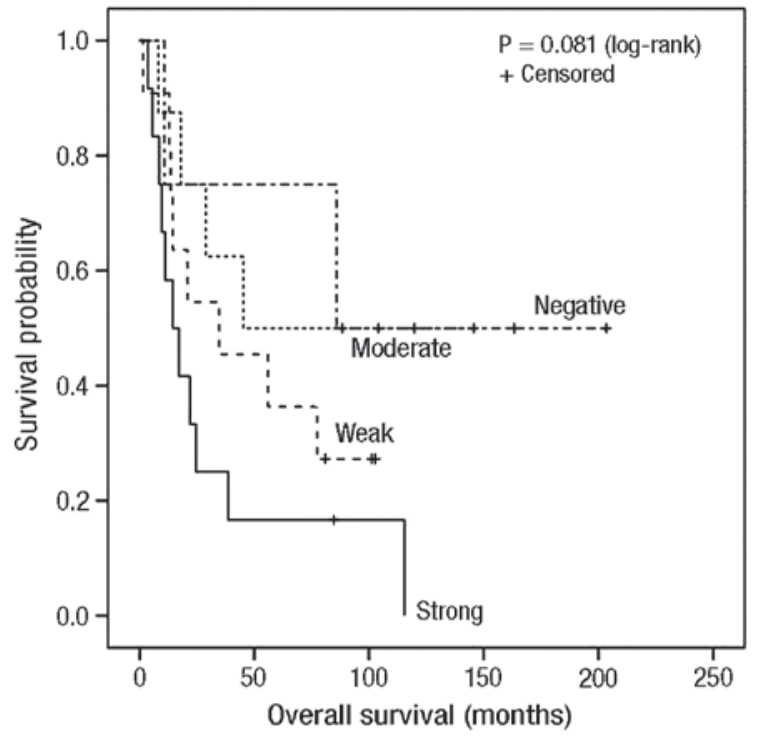

Figure 2. Overall survival of patients according to Sec62 staining proportion $(\mathrm{P}=0.081)$. Patients alive at final follow-up were censored.
$\mathrm{P}=0.557$, respectively) or $\mathrm{PFS}(\mathrm{P}=0.847, \mathrm{P}=0.943$ and $\mathrm{P}=0.560$, respectively). However, strong nuclear expression of survivin showed a weak trend for poorer OS ( $\mathrm{P}=0.079$; Fig. 3), but not PFS ( $\mathrm{P}=0.103)$. Notably, high Sec62 IRS was significantly associated with poorer OS and PFS rates in the present patient cohort ( $\mathrm{P}=0.020$ and $\mathrm{P}=0.028$, respectively; Table IV; Fig. 4).

Subsequently, whether the expression levels of a combination of these markers were associated with a greater difference in PFS and OS compared with the expression of each single protein was analyzed. Due to the relatively small number of clinical samples, only combinations of two different proteins were analyzed, and not combinations of three or more. Initially, the combination of high Sec62 and high nuclear survivin expression appeared to indicate a poorer prognosis for HNSCC patients (PFS, $\mathrm{P}=0.071$; OS, $\mathrm{P}=0.071$; Fig. 5); however, statistical significance was achieved only when considering patients with low Sec62 and low nuclear survivin expression vs. high Sec62 and high nuclear survivin expression (PFS, $\mathrm{P}=0.006$; $\mathrm{OS}, \mathrm{P}=0.009)$. No combinatorial effect was observed for Sec62 and EGFR (PFS, P=0.091; OS, P=0.097), Sec62 and p16 (PFS, 
Table IV. Summary of immunohistochemical expression analysis and influence on survival time in head and neck squamous cell carcinoma patients.

\begin{tabular}{|c|c|c|c|c|}
\hline \multirow[b]{2}{*}{ Expression level } & \multicolumn{2}{|c|}{ Patients } & \multicolumn{2}{|c|}{ P-value } \\
\hline & $\mathrm{n}$ & $\%$ & Overall survival & Progression-free survival \\
\hline Sec62 & & & 0.020 & 0.028 \\
\hline High & 12 & 34 & & \\
\hline Low & 23 & 66 & & \\
\hline Survivin nuc & & & 0.079 & 0.103 \\
\hline High & 19 & 54 & & \\
\hline Low & 16 & 46 & & \\
\hline Survivin cyt & & & 0.785 & 0.943 \\
\hline High & 20 & 57 & & \\
\hline Low & 15 & 43 & & \\
\hline Survivin nuc+cyt & & & 0.338 & 0.270 \\
\hline High & 28 & 80 & & \\
\hline Low & 7 & 20 & & \\
\hline \multicolumn{5}{|l|}{ p16 } \\
\hline Oropharynx, high/low & $5 / 19$ & 21 & 0.248 & 0.245 \\
\hline All cases, high/low & $5 / 30$ & 14 & 0.557 & 0.560 \\
\hline EGFR & & & 0.585 & 0.847 \\
\hline High & 17 & 49 & & \\
\hline Low & 18 & 51 & & \\
\hline
\end{tabular}

Nuc, nuclear; cyt, cytoplasmic; EGFR, epidermal growth factor receptor.
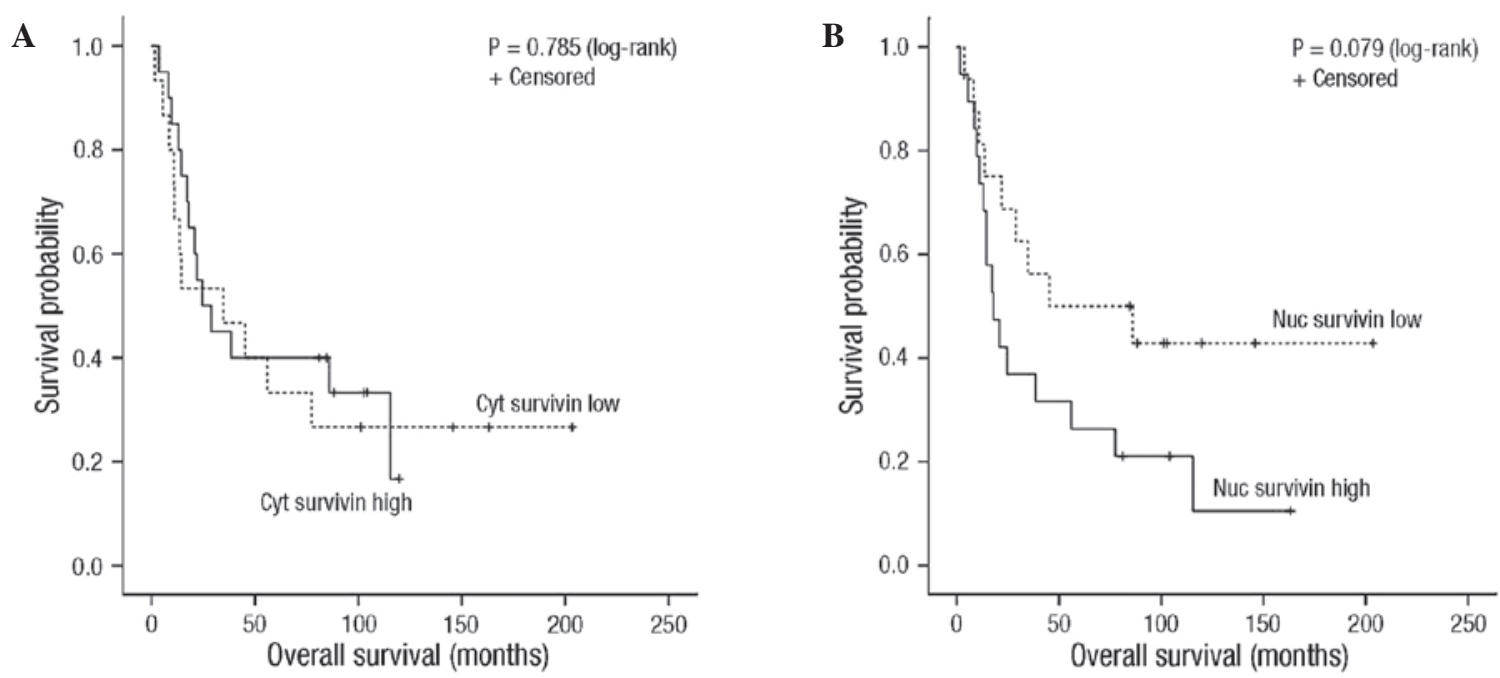

Figure 3. Kaplan-Meier estimates of the probability of overall survival according to (A) cytoplasmic (cyt) survivin and (B) nuclear (nuc) survivin immunostaining. Overexpression of nuclear survivin predicted a weak trend of poorer overall survival in head and neck squamous cell carcinoma patients $(\mathrm{P}=0.079)$. Patients alive at final follow-up were censored.

$\mathrm{P}=0.133 ; \mathrm{OS}, \mathrm{P}=0.095)$, EGFR and $\mathrm{p} 16$ (PFS, $\mathrm{P}=0.928 ; \mathrm{OS}$, $\mathrm{P}=0.841$ ) or $\mathrm{EGFR}$ and survivin ( $\mathrm{PFS}, \mathrm{P}=0.297$; $\mathrm{OS}, \mathrm{P}=0.431$ ).

\section{Discussion}

The purpose of the present study was to characterize the role of Sec62 as a novel potential biomarker for HNSCC, as well as expression of the already extensively discussed biomarkers EGFR, p16 and survivin in a cohort of patients with locally advanced HNSCC treated with CRT.

EGFR is expressed in normal epithelium and has been observed to be upregulated in a number of types of carcinoma (19). High expression levels of EGFR are also a common feature of HNSCC across various anatomical sites to differing 
A

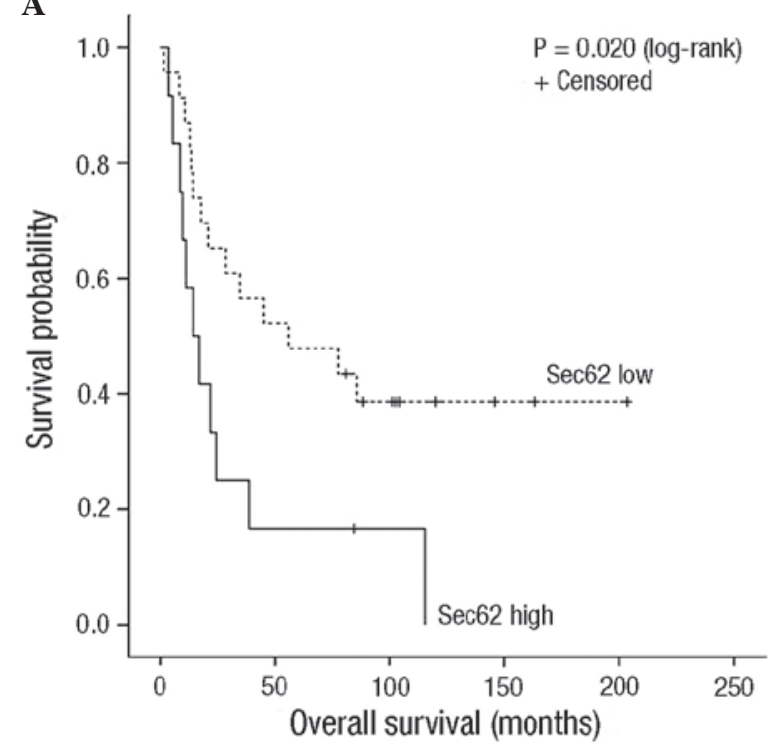

B

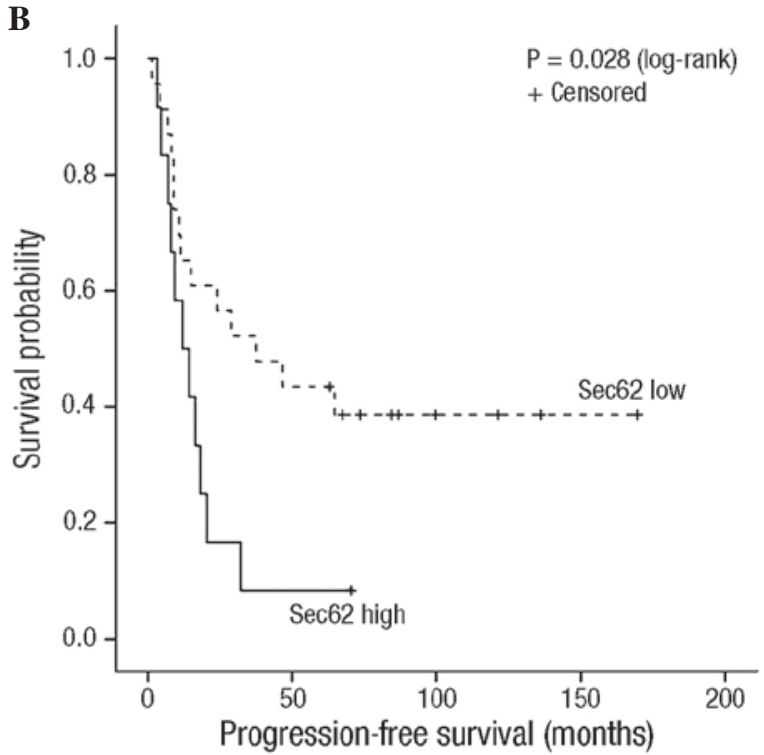

Figure 4. Kaplan-Meier estimates of the probability of (A) overall survival and (B) progression-free survival according to Sec62 immunostaining. Overexpression of Sec62 predicted a poorer overall and progression-free survival in head and neck squamous cell carcinoma patients $(\mathrm{P}=0.020$ and $\mathrm{P}=0.028$, respectively). Patients alive at final follow-up were censored.

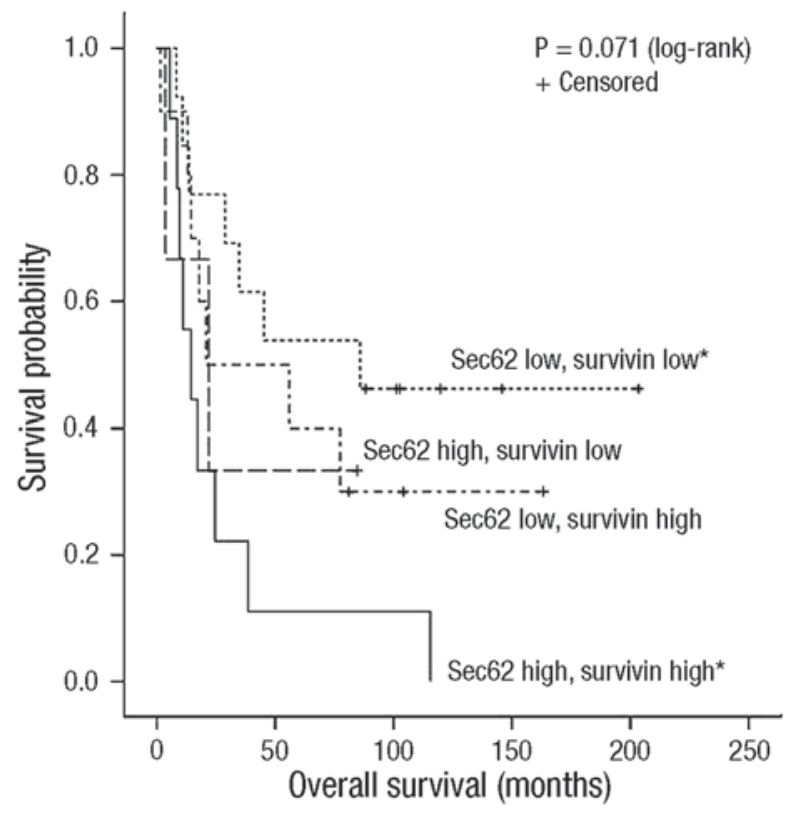

Figure 5. Kaplan-Meier estimates of the probability of overall survival in patients according to the combination of Sec62 and survivin overexpression $(\mathrm{P}=0.071)$. $P$ atients with high Sec62 and high nuclear survivin demonstrated a poorer prognosis compared with patients exhibiting low Sec62 and low nuclear survivin expression $(\mathrm{P}=0.009)$. Patients alive at final follow-up were censored.

degrees $(21,35)$. However, previous studies focusing on the prognostic impact of EGFR expression levels in HNSCC reported varying results $(11,12)$. A number of reasons may account for the discrepant results in terms of the prognostic impact of EGFR expression in HNSCC. These include differences in the anatomical sub-sites of HNSCC, varying sample compositions (biopsies and whole tumor sections) and sample sizes, differing EGFR expression measurement methods, different EGFR immunohistochemical staining protocols and varying scoring methods $(36,37)$. In the present study, no significant correlation between EGFR expression and OS time was observed, which contrasted with the results of the majority of studies that have analyzed and compared EGFR expression in HNSCC $(11,12)$. However, there are results that support the present observations, particularly studies that identified no prognostic significance of EGFR expression when comparing the treatment of HNSCC with radiotherapy or CRT (38-40).

Previous studies have revealed that patients exhibiting HPV-positive HNSCC demonstrate an improved prognosis compared with patients exhibiting virus-negative tumors $(3,28,41-43)$. Previous work by a number of groups has demonstrated that significantly more tumors originating in the oropharynx express p16, a surrogate marker for high-risk HPV infection, compared with non-oropharyngeal sites $(3,41,43)$. Furthermore, previous studies have revealed the prognostic impact of p16 positivity for tumor collectives treated with various treatment modalities, including surgery, radiotherapy and CRT $(3,4,41,43)$, or OSCC treated by various modalities (that were not used to distinguish patients) $(28,42,44)$. This favorable prognosis is hypothesized to be due to a combination of tumor biology, favorable patient characteristics (younger patients with limited comorbidity and positive performance status, and reduced likelihood of tobacco and alcohol abuse in these patients) and an apparent reduced risk of experiencing secondary primary tumors $(28,45)$.

In the present study, p16 expression was restricted to the oropharyngeal sub-site; however, a prognostic influence on survival was not observed. One of the limitations of the present study was the small number of p16-positive tumors $(n=5)$, which may explain the non-significant difference in survival time. The slightly reduced rate as compared with other studies may additionally be the result of varying socioeconomic profiles and risk factors of the patients. Furthermore, previous studies have suggested that the biological behavior of HPV-positive tumors may be altered by tobacco use and may render positive 
tumors less responsive to therapy $(44,45)$. As smoking status was inconsistently recorded in the current patient cohort, this influence could not be analyzed. However, the importance of determining the HPV status in HNSCC, particularly in oropharyngeal cancer, has been extensively demonstrated in the relevant literature and should be considered in additional studies (3-5,28,41-45).

As previously mentioned, survivin is overexpressed in the majority of human tumors; however, is undetectable or present at very low levels in the majority of normal adult tissues (23). Survivin expression has been associated with poor prognosis, disease progression and drug resistance in various types of malignancy, including HNSCC, and particularly in those exhibiting high nuclear survivin expression $(14,17,46)$. However, a number of reports have revealed survivin expression to be associated with favorable prognosis, including in gastric (47) and breast cancer (48), as well as in HNSCC, regardless of the various nuclear and cytoplasmic staining patterns of survivin $(15,16)$. In concordance with the results of several previous studies $(13-15,17,49)$, the present study identified that survivin exists in two subcellular pools, cytoplasmic and nuclear. Studies considering these differences reported a consistent association between high levels of nuclear survivin expression and poor prognosis $(17,49)$. Due potentially to the limited number of patients investigated, the present study could demonstrate only a weak trend between nuclear survivin expression and a reduced OS time, whereas cytoplasmic survivin expression had no prognostic influence.

Multiple reports have described $3 q$ amplification, particularly within the region from $3 \mathrm{q} 22$ to 3 qter, as one of the most common genomic alterations in $\operatorname{HNSCC}(8,10)$, and this amplification has been demonstrated to be associated with more aggressive tumor behaviors and to be predictive of a poorer prognosis $(9,10)$. In NSCLC, the clinical relevance of Sec62, another tumor entity characterized by $3 q$ amplification, has already been demonstrated. A significantly increased Sec62 content was observed in tumors exhibiting lymph node metastases compared with non-metastasized tumors, as well as in poorly differentiated (grade 3) compared with moderately differentiated (grade 2) tumors (31). Furthermore, SEC62 overexpression was associated with significantly reduced OS time in NSCLC patients who underwent curative surgery, particularly in patients exhibiting squamous cell lung carcinoma (32).

In addition to its correlation with a cancerous phenotype and adverse clinical parameters, SEC62 overexpression has been demonstrated to serve a significant functional role in molecular carcinogenesis in vitro; SEC62 silencing by small interfering RNA transfection resulted in a markedly decreased migration capability, as well as increased sensitivity towards ER stress in various cell lines $(29,31)$. Furthermore, artificial SEC62 overexpression in HEK293 cells induced a potential to migrate in this otherwise scarcely migrating cell line (32). Thus, based on current knowledge regarding Sec62 biology in cancer, tumor cells may benefit from an increased Sec62 level with regard to an increased migration potential, as well as an enhanced ability to cope with ER stress $(50,51)$. However, the exact molecular mechanisms by which Sec62 is able to influence the processes of cell migration and ER stress tolerance remain to be elucidated. As Sec62 is known to have a role in protein translocation into the ER, and thereby in the biosynthesis of numerous secretory and membrane proteins (52-54), it may be speculated that the inhibition of cell migration associated with decreased Sec62 protein content may be due to a reduced biogenesis of specific membrane or secretory proteins that are involved in cell migration and ER stress-associated mechanisms. Furthermore, the tumor-promoting effects of Sec62 in cancer cells appear to be mediated, at least in part, by $\mathrm{Ca}^{2+}$-dependent signaling mechanisms (32). A previous study examining various putative oncogenes within $3 q 26$ by systematic loss- and gain-of-function experiments was able to identify SEC62/TLOC1 as a major cancer driver within this frequently amplified region (55).

Notably, in the present study, patients with tumors exhibiting an elevated level of Sec62 and nuclear survivin demonstrated the poorest prognosis. The interaction of survivin with other molecules, such as X-linked inhibitor of apoptosis protein, is known to inhibit the catalytic activity of caspase-9, thereby preventing apoptosis (46). Caspase-9 activation represents a major component of ER stress-induced apoptosis (56), providing an association with Sec62, which is thought to have a significant role in the regulation of $\mathrm{Ca}^{2+}$ leakage from the ER, via indirectly mediating the interaction of the Sec61-channel in the ER membrane with calmodulin on the cytoplasmic side and binding immunoglobulin protein on the ER-luminal side (32). Thus, survivin and Sec62 may synergistically act as potent apoptosis inhibitors, conferring a proliferation advantage to cancer cells. Based on the results of the present study, the simultaneous therapeutic targeting of these two cancer drivers in HNSCC may be suggested to provide a potentially promising therapeutic approach.

The conclusions of the present study indicate that Sec62 is a promising novel candidate for a prognostic marker in HNSCC patients, and additional studies should include larger populations, as well as a comparison of various treatment strategies.

\section{Acknowledgements}

The present study was supported by the Homburger Research Promotion Program HOMFOR 2010 grant (Saarland University Medical Center, Homburg, Germany).

\section{References}

1. Jemal A, Bray F, Center MM, Ferlay J, Ward E and Forman D: Global cancer statistics. CA Cancer J Clin 61: 69-90, 2011.

2. Hashibe M, Brennan P, Chuang SC, Boccia S, Castellsague X, Chen C, Curado MP, Dal Maso L, Daudt AW, Fabianova E, et al: Interaction between tobacco and alcohol use and the risk of head and neck cancer: Pooled analysis in the International Head and Neck Cancer Epidemiology Consortium. Cancer Epidemiol Biomarkers Prev 18: 541-550, 2009.

3. Fakhry C, Westra WH, Li S, Cmelak A, Ridge JA, Pinto H, Forastiere A and Gillison ML: Improved survival of patients with human papillomavirus-positive head and neck squamous cell carcinoma in a prospective clinical trial. J Natl Cancer Inst 100: 261-269, 2008.

4. Ang KK, Harris J, Wheeler R, Weber R, Rosenthal DI, Nguyen-Tân PF, Westra WH, Chung CH, Jordan RC, Lu C, et al: Human papillomavirus and survival of patients with oropharyngeal cancer. N Engl J Med 363: 24-35, 2010.

5. Chung CH and Gillison ML: Human papillomavirus in head and neck cancer: Its role in pathogenesis and clinical implications. Clin Cancer Res 15: 6758-6762, 2009.

6. Nevins JR: The Rb/E2F pathway and cancer. Hum Mol Genet 10: 699-703, 2001. 
7. Burri RJ and Lee NY: Concurrent chemotherapy and radiotherapy for head and neck cancer. Expert Rev Anticancer Ther 9: 293-302, 2009.

8. Bauer VL, Braselmann H, Henke M, Mattern D, Walch A, Unger K, Baudis M, Lassmann S, Huber R, Wienberg J, et al: Chromosomal changes characterize head and neck cancer with poor prognosis. J Mol Med (Berl) 86: 1353-1365, 2008.

9. Wreesmann VB, Shi W, Thaler HT, Poluri A, Kraus DH, Pfister D, Shaha AR, Shah JP, Rao PH and Singh B: Identification of novel prognosticators of outcome in squamous cell carcinoma of the head and neck. J Clin Oncol 22: 3965-3972, 2004.

10. Bockmühl U, Schlüns K, Küchler I, Petersen S and Petersen I: Genetic imbalances with impact on survival in head and neck cancer patients. Am J Pathol 157: 369-375, 2000.

11. Zhu X, Zhang F, Zhang W, He J, Zhao Y and Chen X: Prognostic role of epidermal growth factor receptor in head and neck cancer: A meta-analysis. J Surg Oncol 108: 387-397, 2013.

12. Keren S, Shoude Z, Lu Z and Beibei Y: Role of EGFR as a prognostic factor for survival in head and neck cancer: A meta-analysis. Tumour Biol 35: 2285-2295, 2014.

13. Li F, Yang J, Ramnath N, Javle MM and Tan D: Nuclear or cytoplasmic expression of survivin: What is the significance? Int J Cancer 114: 509-512, 2005.

14. Lo Muzio L, Pannone G, Leonardi R, Staibano S, Mignogna MD, De Rosa G, Kudo Y, Takata T and Altieri DC: Survivin, a potential early predictor of tumor progression in the oral mucosa. J Dent Res 82: 923-928, 2003.

15. Freier K, Pungs S, Sticht C, Flechtenmacher C, Lichter P, Joos S and Hofele C: High survivin expression is associated with favorable outcome in advanced primary oral squamous cell carcinoma after radiation therapy. Int J Cancer 120 942-946, 2007

16. Farnebo L, Tiefenböck K, Ansell A, Thunell LK, Garvin S and Roberg K: Strong expression of survivin is associated with positive response to radiotherapy and improved overall survival in head and neck squamous cell carcinoma patients. Int J Cancer 133: 1994-2003, 2013.

17. Preuss SF, Weinell A, Molitor M, Semrau R, Stenner M, Drebber U, Wedemeyer I, Hoffmann TK, Guntinas-Lichius O and Klussmann JP: Survivin and epidermal growth factor receptor expression in surgically treated oropharyngeal squamous cell carcinoma. Head Neck 30: 1318-1324, 2008.

18. Herbst RS: Review of epidermal growth factor receptor biology. Int J Radiat Oncol Biol Phys 59 (Suppl 2): S21-S26, 2004.

19. Nicholson RI, Gee JM and Harper ME: EGFR and cancer prognosis. Eur J Cancer 37 (Suppl 4): S9-S15, 2001.

20. Rubin Grandis J, Tweardy DJ and Melhem MF: Asynchronous modulation of transforming growth factor alpha and epidermal growth factor receptor protein expression in progression of premalignant lesions to head and neck squamous cell carcinoma. Clin Cancer Res 4: 13-20, 1998.

21. Dassonville O, Formento JL, Francoual M, Ramaioli A, Santini J, Schneider M, Demard F and Milano G: Expression of epidermal growth factor receptor and survival in upper aerodigestive tract cancer. J Clin Oncol 11: 1873-1878, 1993.

22. Li F, Ambrosini G, Chu EY, Plescia J, Tognin S, Marchisio PC and Altieri DC: Control of apoptosis and mitotic spindle checkpoint by survivin. Nature 396: 580-584, 1998.

23. Ambrosini G, Adida C and Altieri DC: A novel anti-apoptosis gene, survivin, expressed in cancer and lymphoma. Nat Med 3: 917-921, 1997.

24. Jung V, Kindich R, Kamradt J, Jung M, Müller M, Schulz WA, Engers R, Unteregger G, Stöckle M, Zimmermann R and Wullich B: Genomic and expression analysis of the 3q25-q26 amplification unit reveals TLOC1/SEC62 as a probable target gene in prostate cancer. Mol Cancer Res 4: 169-176, 2006.

25. Dehan E, Ben-Dor A, Liao W, Lipson D, Frimer H, Rienstein S, Simansky D, Krupsky M, Yaron P, Friedman E, et al: Chromosomal aberrations and gene expression profiles in non-small cell lung cancer. Lung Cancer 56: 175-184, 2007.

26. Chen J, Guo L, Peiffer DA, Zhou L, Chan OT, Bibikova M, Wickham-Garcia E, Lu SH, Zhan Q, Wang-Rodriguez J, et al: Genomic profiling of 766 cancer-related genes in archived esophageal normal and carcinoma tissues. Int J Cancer 122 : 2249-2254, 2008.

27. Thomas LK, Bermejo JL, Vinokurova S, Jensen K, Bierkens M, Steenbergen R, Bergmann M, von Knebel Doeberitz M and Reuschenbach M: Chromosomal gains and losses in human papillomavirus-associated neoplasia of the lower genital tract - a systematic review and meta-analysis. Eur J Cancer 50: 85-98, 2014.
28. Klussmann JP, Mooren JJ, Lehnen M, Claessen SM, Stenner M, Huebbers CU, Weissenborn SJ, Wedemeyer I, Preuss SF, Straetmans JM, et al: Genetic signatures of HPV-related and unrelated oropharyngeal carcinoma and their prognostic implications. Clin Cancer Res 15: 1779-1786, 2009.

29. Greiner M, Kreutzer B, Lang S, Jung V, Cavalié A, Unteregger G, Zimmermann R and Wullich B: Sec62 protein level is crucial for the ER stress tolerance of prostate cancer. Prostate 71 : 1074-1083, 2011

30. Greiner M, Kreutzer B, Jung V, Grobholz R, Hasenfus A, Stöhr RF, Tornillo L, Dudek J, Stöckle M, Unteregger G, et al: Silencing of the SEC62 gene inhibits migratory and invasive potential of various tumor cells. Int J Cancer 128: 2284-2295, 2011.

31. Linxweiler M, Linxweiler J, Barth M, Benedix J, Jung V, Kim YJ, Bohle RM, Zimmermann R and Greiner M: Sec62 bridges the gap from $3 q$ amplification to molecular cell biology in non-small cell lung cancer. Am J Pathol 180: 473-483, 2012.

32. Linxweiler M, Schorr S, Schäuble N, Jung M, Linxweiler J, Langer F, Schäfers HJ, Cavalié A, Zimmermann R and Greiner M: Targeting cell migration and the endoplasmic reticulum stress response with calmodulin antagonists: A clinically tested small molecule phenocopy of SEC62 gene silencing in human tumor cells. BMC Cancer 13: 574-588, 2013.

33. Sobin LH and Wittekind C (eds.): International Union Against Cancer system (UICC). TNM Classification of Malignant Tumours. 6th edition. John Wiley \& Sons, Hoboken, New Jersey, 2002.

34. Remmele W and Stegner HE: Recommendation for uniform definition of an immunoreactive score (IRS) for immunohistochemical estrogen receptor detection (ER-ICA) in breast cancer tissue. Pathologe 8: 138-140, 1987 (In German).

35. Bentzen SM, Atasoy BM, Daley FM, Dische S, Richman PI, Saunders MI, Trott KR and Wilson GD: Epidermal growth factor receptor expression in pretreatment biopsies from head and neck squamous cell carcinoma as a predictive factor for a benefit from accelerated radiation therapy in a randomized controlled trial. J Clin Oncol 23: 5560-5567, 2005.

36. Atkins D, Reiffen KA, Tegtmeier CL, Winther H, Bonato MS and Störkel S: Immunohistochemical detection of EGFR in paraffin-embedded tumor tissues: Variation in staining intensity due to choice of fixative and storage time of tissue sections. J Histochem Cytochem 52: 893-901, 2004.

37. Fischer C, Zlobec I, Stöckli E, Probst S, Storck C, Tornillo L, Lugli A, Wolfensberger $M$ and Terracciano L: Is immunohistochemical epidermal growth factor receptor expression overestimated as a prognostic factor in head-neck squamous cell carcinoma? A retrospective analysis based on a tissue microarray of 365 carcinomas. Hum Pathol 39: 1527-1534, 2008.

38. Numico G, Russi EG, Colantonio I, Lantermo RA, Silvestris N, Vitiello R, Comino A, Abrate M, Zavattero C, Melano A and Merlano M: EGFR status and prognosis of patients with locally advanced head and neck cancer treated with chemoradiotherapy. Anticancer Res 30: 671-676, 2010.

39. Eriksen JG, Steiniche T, Askaa J, Alsner J and Overgaard J: The prognostic value of epidermal growth factor receptor is related to tumor differentiation and the overall treatment time of radiotherapy in squamous cell carcinomas of the head and neck. Int J Radiat Oncol Biol Phys 58: 561-566, 2004.

40. Aebersold DM, Froehlich SC, Jonczy M, Beer KT, Laissue J, Greiner RH and Djonov V: Expression of transforming growth factor-alpha, epidermal growth factor receptor and platelet-derived growth factors A and B in oropharyngeal cancers treated by curative radiation therapy. Radiother Oncol 63: 275-283, 2002

41. Lassen P, Eriksen JG, Hamilton-Dutoit S, Tramm T, Alsner J and Overgaard J: Effect of HPV-associated p16INK4A expression on response to radiotherapy and survival in squamous cell carcinoma of the head and neck. J Clin Oncol 27: 1992-1998, 2009.

42. Fischer CA, Zlobec I, Green E, Probst S, Storck C, Lugli A, Tornillo L, Wolfensberger $\mathrm{M}$ and Terracciano LM: Is the improved prognosis of p16 positive oropharyngeal squamous cell carcinoma dependent of the treatment modality? Int $\mathrm{J}$ Cancer 126: 1256-1262, 2010.

43. Deng Z, Hasegawa M, Aoki K, Matayoshi S, Kiyuna A, Yamashita Y, Uehara T, Agena S, Maeda H, Xie M and Suzuki M: A comprehensive evaluation of human papillomavirus positive status and p16INK4a overexpression as a prognostic biomarker in head and neck squamous cell carcinoma. Int J Oncol 45: $67-76,2014$ 
44. Hafkamp HC, Manni JJ, Haesevoets A, Voogd AC, Schepers M Bot FJ, Hopman AH, Ramaekers FC and Speel EJ: Marked differences in survival rate between smokers and nonsmokers with HPV 16-associated tonsillar carcinomas. Int J Cancer 122: 2656-2664,2008.

45. Gillison ML, Zhang Q, Jordan R, Xiao W, Westra WH, Trotti A, Spencer S, Harris J, Chung CH and Ang KK: Tobacco smoking and increased risk of death and progression for patients with p16-positive and p16-negative oropharyngeal cancer. J Clin Oncol 30: 2102-2111, 2012.

46. Mita AC, Mita MM, Nawrocki ST and Giles FJ: Survivin: Key regulator of mitosis and apoptosis and novel target for cancer therapeutics. Clin Cancer Res 14: 5000-5005, 2008.

47. Okada E, Murai Y, Matsui K, Isizawa S, Cheng C, Masuda M and Takano Y: Survivin expression in tumor cell nuclei is predictive of a favorable prognosis in gastric cancer patients. Cancer Lett 163: 109-116, 2001

48. Kennedy SM, O'Driscoll L, Purcell R, Fitz-Simons N, McDermott EW, Hill AD, O'Higgins NJ, Parkinson M, Linehan R and Clynes M: Prognostic importance of survivin in breast cancer. Br J Cancer 88: 1077-1083, 2003.

49. Qi G, Kudo Y, Ando T, Tsunematsu T, Shimizu N, Siriwardena SB, Yoshida M, Keikhaee MR, Ogawa I and Takata T: Nuclear Survivin expression is correlated with malignant behaviors of head and neck cancer together with Aurora-B. Oral Oncol 46: 263-270, 2010.
50. Koumenis C: ER stress, hypoxia tolerance and tumor progression. Curr Mol Med 6: 55-69, 2006.

51. Bi M, Naczki C, Koritzimsky M, Fels D, Blais J, Hu N, Harding H, Novoa I, Varia M, Raleigh J, et al: ER stress-regulated translation increases tolerance to extreme hypoxia and promotes tumor growth. EMBO J 24: 3470-3481, 2005.

52. Lang S, Benedix J, Fedeles SV, Schorr S, Schirra C, Schäuble N, Jalal C, Greiner M, Hassdenteufel S, Tatzelt J, et al: Different effects of Sec61 $\alpha$, Sec62 and Sec63 depletion on transport of polypeptides into the endoplasmic reticulum of mammalian cells. J Cell Sci 125: 1958-1969, 2012.

53. Lakkaraju AK, Thankappan R, Mary C, Garrison JL, Taunton J and Strub K: Efficient secretion of small proteins in mammalian cells relies on Sec62-dependent posttranslational translocation. Mol Biol Cell 23: 2712-2722, 2012.

54. Reithinger JH, Kim JE and Kim H: Sec62 protein mediates membrane insertion and orientation of moderately hydrophobic signal anchor proteins in the endoplasmic reticulum (ER). J Biol Chem 288: 18058-18067, 2013.

55. Hagerstrand D, Tong A, Schumacher SE, Ilic N, Shen RR, Cheung HW, Vazquez F, Shrestha Y, Kim SY, Giacomelli AO, et al: Systematic interrogation of 3q26 identifies TLOC1 and SKIL as cancer drivers. Cancer Discov 3: 1044-1057, 2013.

56. Jimbo A, Fujita E, Kouroku Y, Ohnishi J, Inohara N, Kuida K, Sakamaki K, Yonehara S and Momoi T: ER stress induces caspase- 8 activation, stimulating cytochrome $c$ release and caspase-9 activation. Exp Cell Res 283: 156-166, 2003. 